\title{
0581 FIRST AID FOR ALL, FIRST AID FOR LIFE: MAKING THE EMPLOYEE CASE FOR FIRST AID
}

R Evens* Correspondence: Golin Harris, Fox Court, 14 Gray's Inn Road, London WC1X BWS, UK

10.1136/ip.2010.029215.581

One year on from the Health and Safety Executive (HSE) changes to UK workplace safety, many businesses are still adapting their processes to adopt these changes and carry out the necessary risk assessments. While some organisations have trained first aid practitioners, this is far too often seen as a tick-box exercise rather than a necessary life skill, meaning that many first aiders fail to keep their skills updated. St John Ambulance research found that $79 \%$ of businesses had periods where no trained first aiders were present. Given that with a blocked airway you have $4 \mathrm{~min}$ to live yet ambulances take an average of 8 min to respond to an emergency, it is important for more workers, if not all, to be first aid competent to provide employees with the necessary protection. Knowledge of key first aid skills can be the difference between life and death the public agrees. In fact our research found that two nearly two thirds (59\%) of people want first aid to be taught in the workplace. By treating first aid as an act of social responsibility, 
rather than a time consuming regulatory task, businesses can help to guarantee a safer environment for their employees, their families and the wider community. Offering companywide first aid training as an employee benefit is just one step towards creating this safer environment. Richard Evens, commercial training director, St John Ambulance, will present the case for employee-wide first aid training, providing examples of businesses that have seen success in this approach. 